\title{
The Status of Spacecraft Bus and Platform Technology Development under the NASA ISPT Program
}

\author{
David J. Anderson \\ NASA Glenn Research Center \\ 21000 Brookpark Road \\ Cleveland, OH 44135 \\ 216-433-8709 \\ David.J.Anderson@nasa.gov
}

John Dankanich

NASA Marshall Space Flight Center

Huntsville, AL 35812

256-544-3441

John.Dankanich@nasa.gov

\author{
Michelle M. Munk \\ NASA Langley Research Center \\ 1 North Dryden Street \\ Hampton, VA 23681 \\ 757-864-2314 \\ Michelle.M.Munk@nasa.gov \\ Louis Glaab \\ NASA Langley Research Center \\ 1 North Dryden Street \\ Hampton, VA 23681 \\ 757-864-1159 \\ Louis.J.Glaab@nasa.gov
}

\author{
Eric Pencil \\ NASA Glenn Research Center \\ 21000 Brookpark Road \\ Cleveland, OH 44135 \\ 216-977-7433 \\ Eric.J.Pencil@nasa.gov \\ Todd Peterson \\ NASA Glenn Research Center \\ 21000 Brookpark Road \\ Cleveland, OH 44135 \\ 216-433-5350 \\ Todd.T.Peterson@nasa.gov
}

\begin{abstract}
The In-Space Propulsion Technology (ISPT) program is developing spacecraft bus and platform technologies that will enable or enhance NASA robotic science missions. The ISPT program is currently developing technology in three areas that include Propulsion System Technologies, Entry Vehicle Technologies, and Systems/Mission Analysis. ISPT's propulsion technologies include: 1) NASA's Evolutionary Xenon Thruster (NEXT) ion propulsion system, a $0.6-7 \mathrm{~kW}$ throttle-able gridded ion system; 2) a Hall-effect electric propulsion (HEP) system for sample return and low cost missions; 3) the Advanced Xenon Flow Control System (AXFS); ultra-lightweight propellant tank technologies (ULTT); and propulsion technologies for a Mars Ascent Vehicle (MAV). The AXFS and ULTT are two component technologies being developed with nearer-term flight infusion in mind, whereas NEXT and the HEP are being developed as EP systems. ISPT's entry vehicle technologies are: 1) Aerocapture technology development with investments in a family of thermal protection system (TPS) materials and structures; guidance, navigation, and control (GN\&C) models of blunt-body rigid aeroshells; and aerothermal effect models; and 2) Multi-mission technologies for Earth Entry Vehicles (MMEEV) for sample return missions. The Systems/Mission Analysis area is focused on developing tools and assessing the application of propulsion, entry vehicle, and spacecraft bus technologies to a wide variety of mission concepts. Several of the ISPT technologies are related to sample return missions and other spacecraft bus technology needs like: MAV propulsion, MMEEV, and electric propulsion. These technologies, as well as Aerocapture, are more vehicle and mission-focused, and present a different set of technology development challenges. These in-space propulsion technologies are applicable, and potentially enabling for future NASA Discovery, New Frontiers, Flagship and sample return missions currently under consideration. This paper provides a brief overview of the ISPT program, describing the development status and technology infusion readiness.
\end{abstract}

TABLE OF CONTENTS

1. INTRODUCTION ..........................................1

2. Electric Propulsion Technologies ......2

3. ENTRY VEHICLE TECHNOLOGIES....................7

4. SPACECRAFT BUS AND SAMPLE RETURN PROPUlSION TECHNOLOGIES ........................10

5. SYSTEM/MISSION ANALYSIS ........................13

6. CONCLUSION ...............................................14

ACKNOWLEDGMENTS....................................14

REFERENCES..................................................14

BIOGRAPHIES............................................18

\section{INTRODUCTION}

Missions carried out for the Planetary Science Division (PSD) of NASA's Science Mission Directorate (SMD) seek to answer important science questions about our Solar System. To enable or significantly enhance PSD's future planetary science missions, the In-Space Propulsion Technology (ISPT) program is developing critical propulsion, entry vehicle, and other spacecraft and platform subsystem technologies. The ISPT program aims to develop technologies in the mid TRL range (TRL 3 to $6+$ range) that have a reasonable chance of reaching maturity in 4-6 years. The objective is to achieve technology readiness level (TRL) 6 and reduce risk sufficiently for mission infusion. ISPT strongly emphasizes developing propulsion products for NASA flight missions that will be ultimately manufactured by industry and made equally available to all potential users for missions and proposals. ISPT focuses on the development of new enabling technologies that cannot be reasonably achieved within the cost or schedule constraints of mission development timelines.

ISPT's technology investment focus has evolved over time. Since 2001 when ISPT was started, ISPT has been 
developing in-space propulsion technologies that will enable and/or benefit near and mid-term NASA robotic science missions by significantly reducing cost, mass, risk, and/or travel times. ISPT technologies will help deliver spacecraft to PSD's future destinations of interest. In 2009, the ISPT program was tasked to start development of propulsionrelated technologies that would enable future sample return missions.

In March, of 2011, the Planetary Science Decadal Survey [1] was released and made many references to ISPT technologies that were initiated in the previous decade such as aerocapture, NEXT, an advanced chemical rocket called AMBR, and advancements made in the areas of astrodynamics, mission trajectory and planning tools. The Decadal Survey validated the technology investments ISPT has made over the last 10 years, and it provides guidance for ISPT's future technology investments.

The Decadal Survey Committee supported NASA developing a multi-mission technology investment program that will "preserve its focus on fundamental system capabilities rather than solely on individual technology tasks." They highlighted the NEXT system development as an example of this "integrated approach" of "advancement of solar electric propulsion systems to enable wide variety of new missions throughout the solar system." The Decadal Survey made a recommendation for "making similar equivalent systems investments" in advanced solar array technology and aerocapture. The Decadal Survey also discussed the importance of developing those system technologies to TRL 6 .

The ISPT program is currently developing technology in four areas. These include Propulsion System Technologies (Electric and Chemical), Entry Vehicle Technologies (Aerocapture and Earth entry vehicles), Spacecraft Bus and Sample Return Propulsion Technologies (components and ascent vehicles), and Systems/Mission Analysis. These inspace propulsion technologies are applicable, and potentially enabling, for future NASA Discovery, New Frontiers, and sample return missions currently under consideration, as well as having broad applicability to potential Flagship missions. This paper describes the technology development in the areas of electric propulsion, Aerocapture, Earth entry vehicles, propulsion components, Mars ascent vehicle, and mission/systems analysis. For more background on ISPT, please see References [2, 3, 4, 5, $6,7,8,9$ and 10].

The ISPT program is currently funded through FY2014, so the focus this year will be concluding on-going efforts, documenting the accomplishments, and systematically closing-out the program. The ISPT program is making a concerted effort to adjust our remaining development activities to improve the infusion paths for ISPT developed technologies. We are being active in seeking out infusion opportunities for the ISPT developed technologies, and are exploring a number of paths to get our technologies out of NASA and into the commercial world. ISPT is also leading or co-leading several strategic planning activities that include a Technology Infusion Study, a TRL Assessment Study, and the formulation of development plans for Halleffect electric propulsion applicable to Discovery-class missions.

\section{Electric Propulsion Technologies}

ISPT's propulsion system technology investments are currently being made in the area of Solar Electric Propulsion (SEP). SEP is both an enabling and enhancing technology for reaching a wide range of targets. Several key missions of interest: sample return, small body rendezvous, multirendezvous, Titan/Saturn System Mission (TSSM), Uranus Orbiter w/Probe, etc., require significant post-launch $\Delta \mathrm{V}$ and therefore can benefit greatly from the use of electric propulsion. [11, 12] High performance in-space propulsion can also enable launch vehicle step down; significantly reducing mission cost. [13] The performances of the electric propulsion systems allow direct trajectories to multiple targets that are otherwise infeasible using chemical propulsion. The technology allows for multiple rendezvous missions in place of fly-bys and, as planned in the Dawn mission, can enable multiple destinations. SEP offers major performance gains, moderate development risk, and significant impact on the capabilities of new missions. ISPT's approach to the development of chemical propulsion technologies is primarily the evolution of component technologies that still offer significant performance improvements relative to state-of-art technologies. The investments focus on items that would provide performance benefit with minimal risk with respect to the technology being incorporated into future fight systems.

\section{NASA's Evolutionary Xenon Thruster (NEXT)}

Current plans include completion of the NEXT Ion Propulsion System targeted at Flagship, New Frontiers and demanding Discovery missions. The GRC-led NEXT project was competitively selected to develop a nominal 40$\mathrm{cm}$ gridded-ion electric propulsion system. [2] The objectives of this development were 1) to improve upon the state-of-art (SOA) NASA Solar Electric Propulsion Technology Application Readiness (NSTAR) system flown on Deep Space-1 and Dawn, 2) to enable flagship class missions by achieving the performance characteristics listed in Table 1.

Table 1. Performance comparison of NSTAR and NEXT ion thrusters

\begin{tabular}{|lcc|}
\hline \multicolumn{1}{|c}{ Characteristic } & $\begin{array}{c}\text { NSTAR } \\
\text { (SOA) }\end{array}$ & NEXT \\
\hline Max. Thruster Power (kW) & 2.3 & 6.9 \\
\hline Max. Thrust (mN) & 91 & 236 \\
\hline Throttle Range (Max./Min. Thrust) & 4.9 & 13.8 \\
\hline Max. Specific Impulse (sec) & 3120 & 4190 \\
\hline Total Impulse (x10 ${ }^{6}$ N-sec) & $>5$ & $>34.9$ \\
\hline Propellant Throughput (kg) & 200 & 902 \\
\hline
\end{tabular}




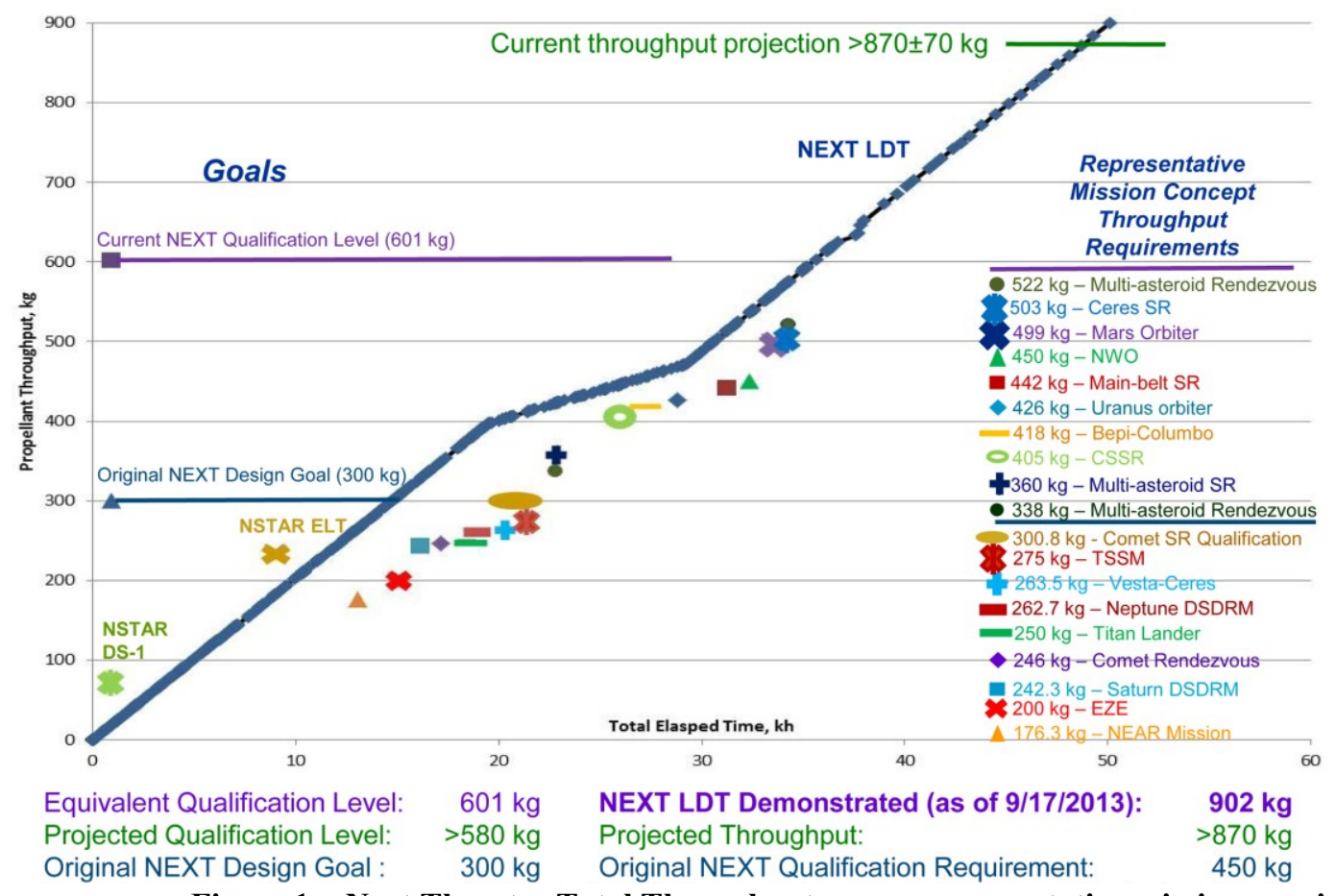

Figure 1 - Next Thruster Total Throughput versus representative mission requirements

The ion propulsion system components developed under the NEXT task include the ion thruster, the power-processing unit (PPU), the feed system, and a gimbal mechanism. The NEXT project is developing prototype-model (PM) fidelity thrusters through the Aerojet Corporation. In addition to the technical goals, the project has the goal of transitioning thruster-manufacturing capability with predictable yields to an industrial source. To demonstrate the performance and life of the NEXT thruster, a test program is underway. The NEXT PM thruster completed a short-duration test in which overall ion-engine performance was steady with no indication of performance degradation. A NEXT PM thruster has passed qualification level environmental testing. As of September 17, 2013 the Long Duration Test (LDT) of the NEXT engineering model (EM) thruster achieved over 902-kg xenon throughput, $34.9 \times 10^{6} \mathrm{~N}-\mathrm{s}$ of total impulse, and over 50,197 hours at multiple throttle conditions (Figure 1). The NEXT LDT wear test has set the world record by demonstrating the largest total impulse ever achieved by a gridded-ion thruster.

ISPT funding for the thruster life test continues into FY14. The goal was to demonstrate thruster operation to $800 \mathrm{~kg}$ which, depending on the relative rates of the pit and groove erosion of the screen grid, may or may not represent the end-of-life condition for the NEXT thruster. The facility impact assessment review for the NEXT LDT assessed the impact of back-sputtered carbon on accelerator grid erosion rates. Analysis results showed that back-sputtered carbon reduced accelerator grid wear by less than four percent. Enhanced charge-exchange impact analysis determined approximately 8 to 10 percent increase for charge-exchange.
Repair of the NEXT LDT diagnostics equipment was initiated in November 2013. The equipment wore out over the eight-year test. The purpose was to collect end-of-test data with a fully functional diagnostic suite to compare with beginning-of-life data. The NEXT LDT diagnostics suite is shown in Figure 2. Equipment repaired is listed below:

(1) Repair of the planar probe rake: to measure near-field current densities, provide an independently verified beam current, and assess potential changes in divergence

(2) Repair Residual Gas Analyzer (RGA): to determine changes in background gas pressures that can affect thruster erosion and life

(3) Replacement of the QCM: to determine changes in back-sputter rates

(4) Replace Ion gage next to thruster: to confirm pressure changes near thruster (wall mounted gages still functional)

(5) Replace coated facility windows: to photo-document thruster clearly, and image grid gap \& groove erosion patterns

(6) Improved imaging system lighting: to measure grid aperture diameters (downstream chamfers) \& Discharge Cathode Assemble (DCA) orifices

The final end-of-test characterization of the NEXT LDT began in December 2013 with the full diagnostics suite. The restart sequence went smoothly with no issues. The LDT is presently at 50,520 hours of high-voltage operation, corresponding to $909 \mathrm{~kg}$ of processed xenon and 35.1 MN-s 
of total impulse delivered. Data collection is expected to be completed by early to mid-January. This will be followed by removal of the test article for destructive post-test analyses in atmosphere in late FY14. [14]
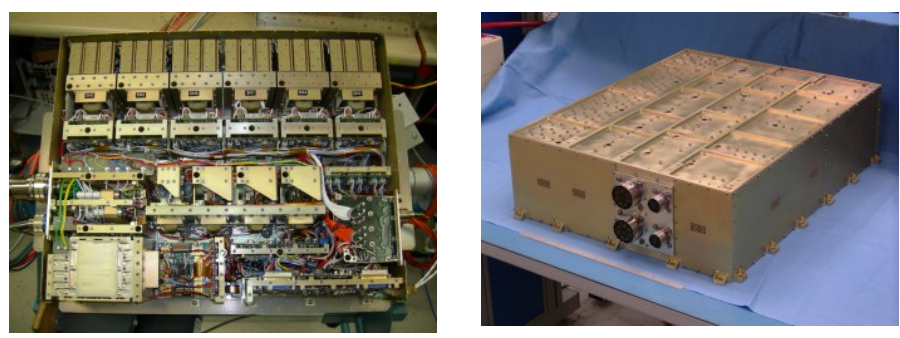

Figure 3 - NEXT PPU developmental unit

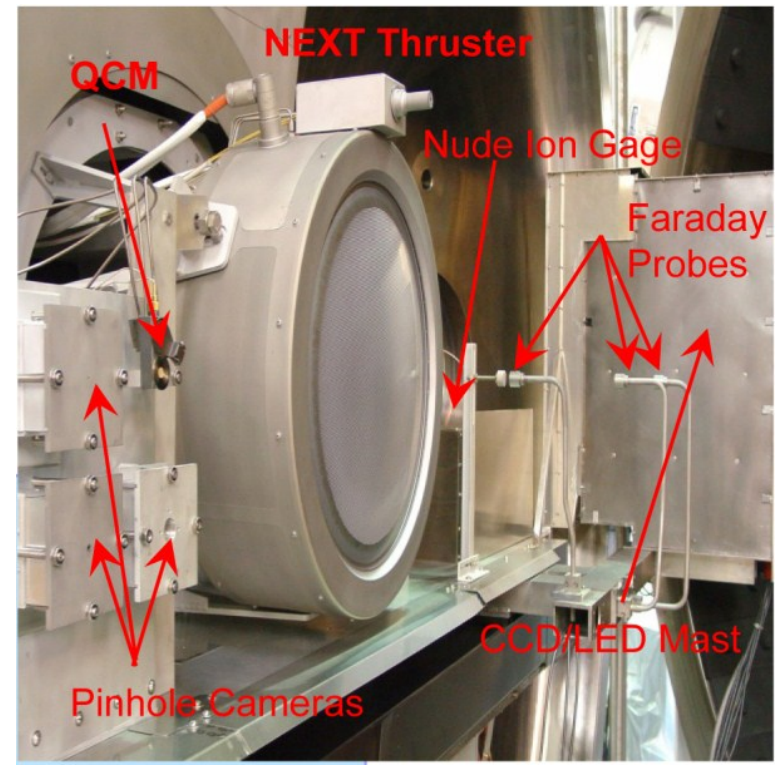

Figure 2 - NEXT LDT Diagnostics

One of the challenges of developing the NEXT ion propulsion system was the development of the Engineering Model PPU. The demanding test program has flushed out a number of part problems that required extensive investigations to resolve and implement corrective actions. [15] It should be noted that such part problems are not unique in a technology development phase, and can still be experienced in the transition-to-flight hardware development phase. Technology development projects like NEXT are attempting to identify and mitigate these kinds of issues, before the PPU moves into a flight development phase.

One of the recent PPU part problems was the catastrophic failure of the multi-layer ceramic (MLC) capacitor in multiple beam power supplies. The investigation process utilized an extensive and knowledgeable team that investigated all branches of the fault tree. The corrective actions identified that a custom-built MLC had piezoelectric properties that made it susceptible to an oscillating current in the beam supply circuit. The corrective actions in this case were to replace the custom-build MLC capacitor as well as to eliminate the oscillating current. Recently, another part problem was uncovered, which manifested itself as a shorted diode. The diagnosis was that a void in the printed circuit board contributed to an overvoltage condition on the diode that caused it to short. This conclusion was confirmed with $\mathrm{x}$-ray inspection of the printed circuit board. The corrective actions for the MLC capacitor issues were implemented in the EM PPU, and resolved the problems. The PPU has been refurbished to complete the planned test matrix, which includes PPUthruster integration testing, electromagnetic interference testing, and breadboard digital control interface unit (DCIU) integration tests. The NEXT PPU is shown in Figure 3.

An area in which further NEXT work has been needed is that of precise plume, particle, and field characterization. A non- reimbursable Space Act Agreement (SAA) was drafted by NASA and The Aerospace Corporation (TAC) to establish a collaborative measurement program intended to examine the plume, particle, and field environments of the latest generation NASA ion propulsion technology. A series of measurements has been completed to verify basic characteristics of NEXT operation and expand on the available public-domain and internal databases regarding NASA technology and its potential use on non-NASA spacecraft systems. [16] Figure 4 shows the NEXT thruster installed in the vacuum facility at TAC. Among the work elements planned are in-depth EMI/EMC, plume particle and plasma probe, optical emission and laser diagnostic measurements. This work is of considerable relevance to future spacecraft integration of the subject thrusters.

The NEXT evaluation at Aerospace also includes measurement of ion beam flux and divergence, charge state ratios, charge exchange ion flux, plume optical emission spectrum and absolute flux, radio frequency and microwave absolute emission spectrum plus timedomain emissions, carrier wave attenuation and phase

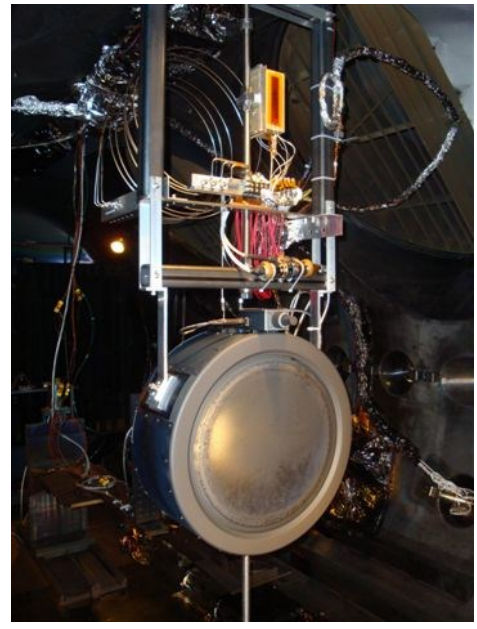

Figure 4 - NEXT characterization testing at TAC effects, plume erosion and molybdenum contamination effects, absolute thrust and thrust correction factors. Plume characterization tests with the NEXT ion thruster were performed using the EM and 
PM thrusters. Examinations of the beam current density and xenon charge-state distribution as functions of position on the accelerator grid have been completed. [17] The angular dependence of beam current was measured at intermediate and far-field distances to assist with plume modeling and to evaluate the thrust loss due to beam divergence. Thrust correction factors were derived from the data. [17] Transmission and phase noise measurements were made through the plume of an EM NEXT ion thruster. [18] Attenuation measurements were taken at multiple operating points at frequencies between 1 and $18 \mathrm{GHz}$. Attenuation was observed between 1 and $3 \mathrm{GHz}$ and scaled with plasma density. [18] Phase noise spectra were also taken. Direct thrust measurements have been made on the NEXT PM ion thruster using a standard pendulum style thrust stand constructed specifically for this application. [19, 20] Values have been obtained for the full 40-level throttle table as well as for a few off-nominal operating conditions. $[19,20]$

A particle-based model with a Monte Carlo collision model has been developed by Wright State University (WSU) to study the plasma inside the discharge model of the generic ion thruster. This model tracks five major particle types inside the discharge chamber in detail: xenon neutrals, singly and doubly charged xenon ions, secondary electrons and primary electrons. [21] Both electric and magnetic field effects are included in the calculation of the charged particle's motion. Validation of this computational model has been made with comparisons to the NSTAR discharge chamber. Comparison of numerical simulation results with experimental measurements was found to have good agreement. [21] The model has been applied to the NEXT discharge chamber design at multiple thruster operating conditions. [22, 23, 24, 25, 26]

A Close-out Review of NEXT NRA Phase 2 was conducted in 2012. Feedback from the customer community was provided. The primary remaining concern is completion of the development of the NEXT power processing unit. Additional information on the NEXT system can be found in the NEXT Ion Propulsion System Information Summary in the New Frontiers and Discovery Program libraries. [27, 28, 14, 29, 30]

\section{Electric Propulsion for Sample Return and Discovery-class Missions}

ISPT is investing propulsion technologies for applications to low-cost Discovery-class missions and Earth-Return Vehicles for large and small bodies. The first example leverages the development of a HighVoltage Hall Accelerator (HIVHAC) thruster into a lower-cost electric propulsion system. [3, 30] HIVHAC is the first NASA electric

propulsion thruster specifically designed as a low-cost electric propulsion option. It targets Discovery and New Frontiers missions and smaller mission classes. The HIVHAC thruster does not provide as high a maximum specific impulse as NEXT, but the higher thrust-to-power and lower power requirements are suited for the demands of some Discovery-class missions and sample return applications.

Advancements in the HIVHAC thruster include a large throttle range from $0.3-3.9 \mathrm{~kW}$ allowing for a low power operation. It results in the potential for smaller solar arrays at cost savings, and a long-life capability to allow for greater total impulse with fewer thrusters. The benefits include cost savings with a reduced part count and less-complex lowercost propulsion system.

Wear tests of the NASA-103M.XL

thruster validated and demonstrated a means to mitigate discharge channel erosion as a life-limiting

mechanism in Hall thrusters. The thruster, operated in excess of 5500 hours $(115 \mathrm{~kg}$ of xenon throughput) at a higher specific impulse (thruster operating voltage) as compared to SOA Hall thrusters.

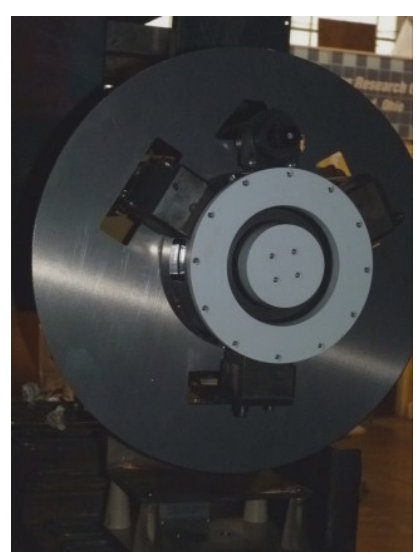

Figure 5 - HIVHAC thruster Engineering Development Unit (EDU)

Components for two Engineering Development Units (EDU-1) thrusters were designed and fabricated. Preliminary performance mapping of the EDU-1 thruster at various operating conditions was performed at NASA Glenn Research Center (GRC) as shown in Figures 5 and 6. [3, 31] The EDU-1 thruster hardware was operated in vacuum test environments for operations and performance assessments. The results indicated that several design changes were needed to resolve problems with thermal design, boronnitride advancement mechanisms, magnetic topology, and high-voltage isolation. A list of rework items was compiled

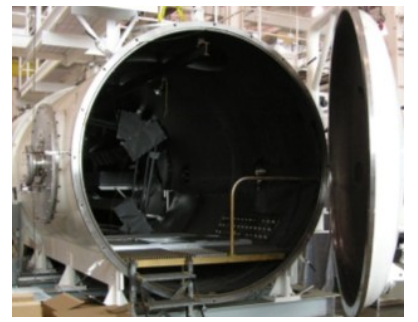

Figure 6 - HIVHAC EDU Thruster and Colorado Power SBIR PPU undergoing performance testing.

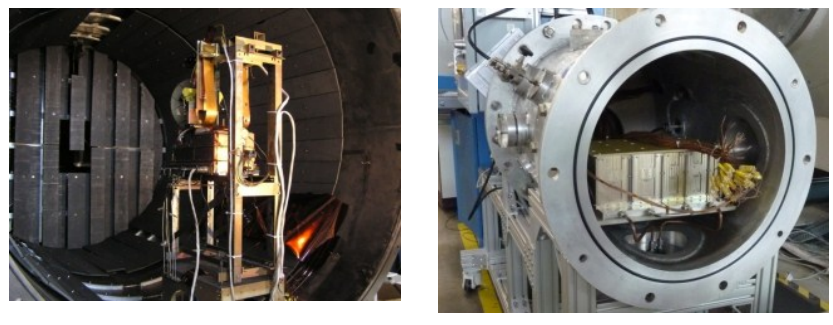


and design corrections were identified and evaluated by either analysis and/or test.

The design improvements were implemented in a reworked engineering model design, which is designated as EDU-2. Vacuum Facility 12 (VF-12) was used to conduct the official performance acceptance test (PAT), given the pumping speed and resulting vacuum chamber background pressure. The results indicate that performance and operational requirements met expectations, with significant improvement to the thermal margins of key components. Vibration testing was completed with performance tests conducted both before and after vibration tests. The HIVHAC EMR thruster was successfully vibrated to approximately $11.5 \mathrm{~g}$ in three axes, which were consistent with the specifications used to qualify the NASA Evolutionary Xenon Thruster ion thruster. Preliminary visual inspection of the thruster indicates that the thruster passed the vibration testing with no visual damage evident and no change in thruster performance was measured.

Single String Integration Test of the NASA HIVHAC Hall thruster was conducted in NASA GRC VF5. During the test a number of plasma diagnostics were implemented to study the effect of varying the facility background pressure on thruster operation. These diagnostics include thrust stand, Faraday probe, ExB probe, and retarding potential analyzer. The test results indicated a rise in thrust and discharge current with background pressure. There was a decrease in ion energy per charge, an increase in multiply-charged species production, a decrease in plume divergence, and a decrease in ion beam current with increasing background pressure. A simplified ingestion model was applied to determine the maximum acceptable background pressure for thrust measurement. The maximum acceptable ingestion percentage was found to be around one percent. Examination of the diagnostics results suggest the ionization and acceleration zones of the thruster were shifting upstream with increasing background pressure. [32]

The HIVHAC EDU-2 thruster advancement mechanism on inner and outer boron nitrate channels was successfully demonstrated immediately after thruster hot-fire operation in VF-12. The advancement mechanism showed smooth advancement of both channels as a full qualification vibration test post-test validation of the mechanism. The actuation test was conducted immediately following thruster shutdown, assuring high-temperature conditions within the thruster. In the future, the test sequence will include performance acceptance tests, the remaining thermal vacuum environmental tests, and a long duration wear test. Current plans include the design, fabrication and assembly of a full Hall propulsion system that can meet a variety of Discovery and Earth Return Vehicle needs.

In addition to the thruster development, the HIVHAC project is evaluating power processing unit (PPU) and xenon feed system (XFS) development options. These were developed under other efforts, but can apply directly to a Hall Propulsion system. The goal is to advance the TRL level of key components of a Hall propulsion system (thruster, PPU/DCIU, feed system) to level 6 in preparation for a first flight.

The functional requirements of a HIVHAC PPU (Figure 4) are operation over a power throttling range of 300 to 3,800 $\mathrm{W}$, over a range of output voltages between 200 and $700 \mathrm{~V}$, and output currents between 1.4 and $5 \mathrm{~A}$ as the input varies over a range of 80 to $160 \mathrm{~V}$. A performance map across these demanding conditions was generated for one candidate option $[3,30]$ that is being developed through NASA Small Business Innovation Research (SBIR) Program. In 2013 a second brass board unit was received from Colorado Power Electronics. Over 1700 hours of steady-state operation under vacuum conditions have been accumulated on this unit. Beyond conventional feed system options, one option for feed systems that was demonstrated with the Hall thruster is the advanced xenon feed system developed by VACCO.

To continue to simplify and reduce the cost of the HIVHAC system, the ISPT program invested in its reliable, lightweight, and low-cost xenon flow control system. [33] A follow-on contract was awarded to VACCO as a joint ISPT and Air Force effort to qualify a Hall system flow control module. This module would significantly reduce the cost, mass, and volume of a Hall thruster xenon control system while maintaining high reliability and decreasing tank residuals. This is the first time the ISPT program advanced a component technology to TRL 8 to further reduce the risk and cost of the first user. The new Hall module, shown in Figure 7, completed its qualification program in June 2012. The module is then planned for inclusion in a HIVHAC thruster long duration wear test along with the SBIR PPU as an integrated string test of the HIVHAC system. A joint ISPT/Air Force team participated in a Preliminary Design Review (PDR) of the VACCO Smart Flow Control Module (SFCM) for infusion into a commercial spacecraft bus using electric propulsion. The module is expected to significantly reduce the xenon feed system complexity, cost, and cycle time. A Critical Design Review (CDR) was completed and the delivery of first qualification test unit is anticipated in November 2013.

The Near-Earth Object (NEO) mission was evaluated, and the HIVHAC thruster system delivered over 30 percent more mass than the NSTAR system. The performance

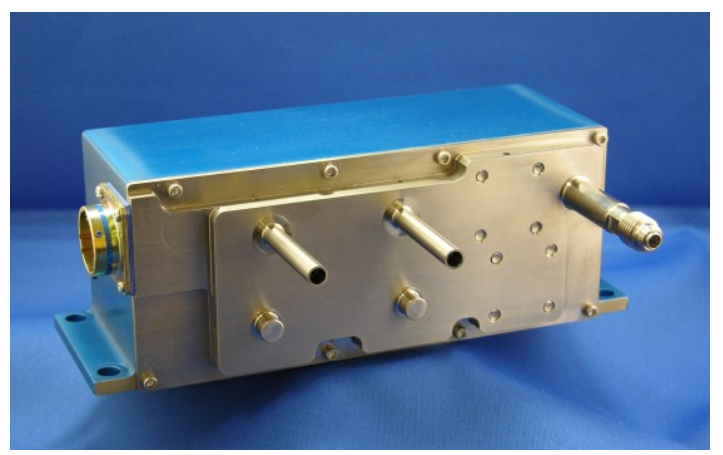

Figure 7 - Hall thruster xenon flow control module. 
increase accompanied a cost savings of approximately 25 percent over the SOA NSTAR system. The Dawn mission was evaluated, and the expected HIVHAC Hall thruster delivered approximately 14 percent more mass at substantially lower cost than SOA, or decreasing the solar array provided equivalent performance at even greater mission cost savings. [3, 31]

The second technology example of a Sample Return Propulsion Technology is the BPT-4000 Hall thruster development. ISPT has invested in a life-test extension of the thruster to improve total impulse demonstrated capabilities. Under evaluation is the operation of this thruster design at higher operating voltages, which improve thruster specific impulse. There are mission studies that indicate that BPT-4000 is directly applicable to ERV and Discovery-class missions.

A Hall system Technical Interchange Meeting (TIM) was held December 2013 to discuss the state of recent Hall thruster testing and development. The following priorities were identified:

1) Develop common flight Hall $5 \mathrm{~kW}$-class modular PPU with capabilities for PSD mission needs for any Hall thruster (COTS or NASA developed), and qualify unit and procure 3 flight PPU's as GFE

2) Evaluate commercial Hall thrusters (BPT-4000 (XR-5), SPT-140)

a. Delta qualify (as necessary) for PSD environments/life

b. Facility effects assessment

c. Ground-test-to-flight-modeling protocols

3) Complete HIVHAC system

a. Assess/incorporate magnetic shielding, and qualify thruster

4) Leverage STMD Hall system to PSD mission needs

5) Maintain Mission analysis capabilities and tool development for SEP

For more HIVHAC information, see References [32, 34, 35, $36,37,38]$.

\section{ENTRY VehicLE TECHNOLOGIES}

\section{Multi-Mission Earth Entry Vehicle (MMEEV)}

The Entry Vehicle Technologies (EVT) project has been developing the Entry, Descent, and Landing (EDL) trade space and system analysis tools for the Multi-Mission Earth Entry Vehicle (MMEEV). The Multi-Mission Earth Entry Vehicle (MMEEV) is a flexible design concept. It can be optimized or tailored by any sample return mission, including lunar, asteroid, comet, and planetary (e.g. Mars), to meet that mission's specific requirements. The Mars Sample Return (MSR) Earth Entry Vehicle (EEV) design, due to planetary protection requirements, is designed to be the most reliable space vehicle ever flown. Other EEVs have different and less restrictive requirements. The MMEEV approach provides an effective foundation for many sample return missions. By leveraging common design elements, this approach can significantly reduce the risk and associated cost in development across all sample return missions. [4]

Detailed studies show that to meet the stringent containment requirements for a Mars sample return mission, the MMEEV should possess three particular design attributes. First, the vehicle aerodynamics must be very well understood. This means utilizing a shape with extensive analysis, testing, and flight experience. The vehicle aerodynamics must also be "self-righting." It needs to quickly stabilize itself in a heatshield-forward orientation in the event of perturbations. Second, the heat shield TPS needs to be robust and have a high level of reliability derived from developmental testing and flight test heritage for both nominal and off-nominal (such as MMOD impacts) environments. The reliability requirement has traditionally implied the use of heritage carbon phenolic TPS, which is limited in supply and manufacturability. NASA has held two workshops, in 2010 and 2012, to assess the availability of carbon phenolic and possible replacement materials. The forward path will depend on funding availability, and is not yet defined. Third, the MMEEV has no limited-reliability system, such as a parachute or other deployable drag device that could fail upon entry.

While these design attributes were developed from MSR applications, they also work well for many other EEV missions providing an optimum balance of cost, risk, and payload requirements. The current MMEEV parametric configuration is presented in Figure 8 (basic vehicle architecture), and Table 2 (parametric variables). Because each individual sample return mission may have a unique set of performance metrics of highest interest, the goal is to provide a qualitative performance comparison across a specified trade space. Each sample return mission can then select the most desirable design point to begin a more optimized design.

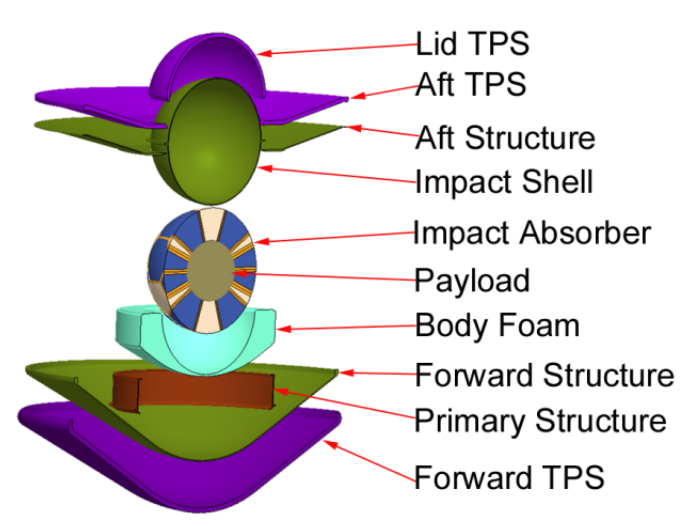

Figure 8 - Basic MMEEV architecture

MMEEV performance studies were integrated into the "Multi-Mission Systems Analysis for Planetary Entry" (MSAPE) Tool. This is a low-fidelity EDL analysis tool that provides mission designers the ability to perform extensive 
trade analyses very early in the design process. The MSAPE tool does contain low-, mid-, and high-fidelity models. However the M-SAPE tool contains at least lowfidelity models for vehicle geometry, flight mechanics,

Table 2. MMEEV parametric variables

\begin{tabular}{|l|l|}
\hline Parametric Variable & Range \\
\hline Payload & 5 to $30 \mathrm{~kg}$ \\
\hline Vehicle Diameter & 0.5 to $2.5 \mathrm{~m}$ \\
\hline Inertial Entry Velocity & 10 to $16 \mathrm{~km} / \mathrm{s}$ \\
\hline Inertial Entry Flight Path Angle & $-5^{\circ}$ to $-25^{\circ}$ \\
\hline
\end{tabular}

structures, aerodynamics, aerothermodynamics, thermal protection systems (TPS), impact attenuation, and thermal soak. High-fidelity validated thermal protection system response models (FIAT) and trajectory simulation tools (POST) are incorporated into M-SAPE which enable highfidelity analysis of certain aspects of the vehicle trade space. [39] Plans for the next year of development include incorporating results from FY-13 wind-tunnel tests in the LaRC 20-FT Vertical Spin Tunnel and subsequent release of the M-SAPE tool and MMEEV design database to the user community. Recent model developments and validation testing include thermal soak model analysis and impact foam sample tests.

A parametric preliminary thermal soak model was developed at NASA-Ames to define the thermal environment of the returned sample canister after the vehicle experiences the heat pulse and subsequent impact and waits to be recovered. [40] Samples from various comets, asteroids, and planets may have differing thermal requirements and impact g-load requirements to preserve the science return. Active thermal control is considered for applications with extreme thermal requirements, though not currently modeled in M-SAPE. Feeding into the thermal soak model is actual test data on impact foams. Several closed-cell foam candidates have been impact tested [41] at NASA-Langley. Thermal conductivity testing of these impact foams have been completed at Southern Research Institute (SRI) in FY-13 in both the virgin and post-impact condition [42]. Results indicate that the effect of impact is to increase the foam's density by $\sim 100$ percent while not significantly affecting thermal conductivity. This result is believed to be due to the venting of the manufacturing gases and replacement with air during impact.. These parameters for various materials will be part of the closed-loop MSAPE analysis capability. Finally, usable subsonic center of gravity limits and an aerodynamic model for an array of MMEEV designs will be established via spin tunnel testing at the NASA-Langley 20-FT Vertical Spin Tunnel (Figure 9). This type of subsonic test, combined with aerodynamic parameter identification (PID) techniques provides unique dynamic aerodynamic results without the interference of a sting. Dynamically scaled vehicle models with various aftbody configurations (i.e., payload sizes) were tested in 2013. A video-based motion tracking system installed in the 20-FT VST provided location and attitude of the freeflying vehicle at $150 \mathrm{~Hz}$. Post-processing PID techniques were applied to provide dynamic and static aerodynamic coefficients for the various vehicle geometries and mass characteristics.

The goal of this work is to provide tools for evaluating MMEEV designs and trade space in support of mission proposal development and preliminary design. Development and use of the capabilities will enable New Frontiers and Discovery missions to cost-effectively perform proposal development and preliminary design analyses. Although Science Mission Directorate management and the ISPT

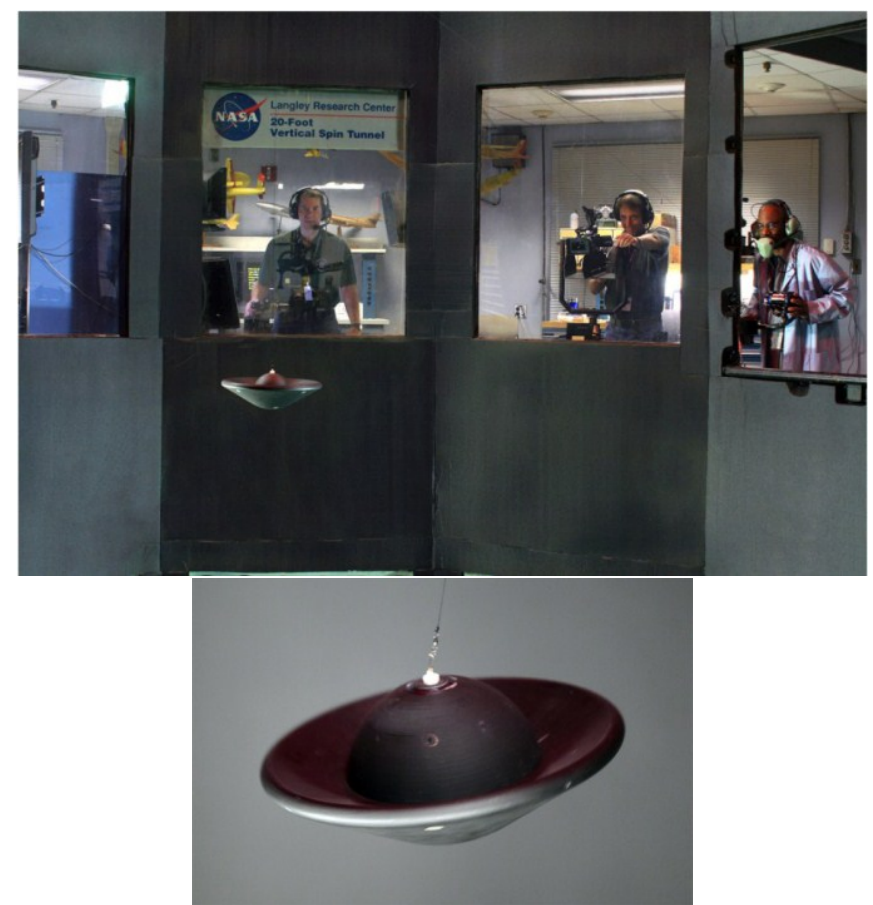

Figure 9 - Vertical Spin Tunnel MMEEV Model and Testing

project team favor this approach, there are currently no manifested missions that use the MMEEV design.

\section{Aerocapture}

Aerocapture is the process of using the destination planet's atmosphere to decelerate the vehicle from aerodynamic forces to capture the spacecraft in a desirable orbit from a hyperbolic trajectory. Aerobraking is a gradual series of passes through the upper atmosphere (once a spacecraft is propulsively captured into a high ellipse) to reduce orbital energy. Aerocapture is capable of much larger decelerations and maximizes the benefit from the atmosphere by capturing a useful science orbit in a single pass. During Aerocapture, as a spacecraft flies at a lower altitude where the atmosphere is denser, the resultant drag and heating is much higher than for aerobraking. Aerocapture heat loads are generally much higher than for nominal entry, descent, and landing, atmospheric entries. An aeroshell is required to both protect the spacecraft from the environment, and provide an aerodynamic surface for control during the pass. 
Keys to successful aerocapture are accurate arrival state knowledge, validated atmospheric models, sufficient vehicle control authority (i.e. lift-to-drag ratio), and robust guidance during the maneuver. A lightweight thermal protection system and structure will maximize the aerocapture mass benefits. Aerocapture significantly reduces the chemical propulsion requirements of an orbit capture.

Aerocapture has shown repeatedly in detailed analyses to be an enabling or strongly enhancing technology for several targets with atmospheres. ISPT has been investing to mature Aerocapture subsystems since 2001. [4] The aerocapture project team continues to mature aerocapture components. A rapid aerocapture analysis tool has been developed and made available to the user community. The TPS materials developed through ISPT enhance a wide range of missions by reducing the mass of entry vehicles. All of the component technologies for an aerocapture vehicle are currently at TRL 5-6. This assessment of technology readiness is detailed in Reference [43]. The structures and TPS subsystems as well as the aerodynamic and aerothermodynamic tools and methods can be applied to planetary entry, descent, and landing or aerocapture applications.

As flight aeroshells become larger (over 3 meters in diameter), it is more difficult to hand-pack them, as was done with the Apollo capsules and every successful Mars heatshield before the Mars Science Laboratory (MSL). ARA developed a modular TPS approach, in which large modules of TPS are pre-packed into honeycomb, cured, and precisely milled to fit the aeroshell structure. Because SRAM and PhenCarb are somewhat elastic, a small number of modules (less than ten) are needed to cover the aeroshell (compared to tens of PICA segments used on MSL). Gaps between modules were packed with the same ablator and cured. The result is a seamless heatshield. To mature this approach, ISPT has manufactured a 2.65-meter (Discovery-class size) low-density Aeroshell (Figure 10). The TPS is applied to the ATK $400{ }^{\circ} \mathrm{C}$ bondline structure. Lawrence Livermore National Laboratory (LLNL) scientists performed nondestructive Computed Tomography (CT) scan of the completed aeroshell to mature the diagnostics methodology and verify the manufacturing methods. Figure 11 shows the 2.65-m Aeroshell with LLNL LINAC CT scan radiation source in the background. Analysis of the results will be completed in FY-14. Manufacturing at this scale will mature the high-temperature aeroshell system to TRL 5. Plans for FY-14 call for a comprehensive closeout of Aerocapture technology development performed under ISPT.

Another effort to raise the TRL for TPS materials, both for Aerocapture and other applications, includes Space Environmental Effects (SEE) testing. Conducted at the Marshall Space Flight Center and the White Sands Test Facility (WSTF), this testing includes radiation exposure, cold soak, and $7 \mathrm{~km} / \mathrm{s}$ micrometeoroid impact on the ISPTmatured TPS for forebodies and backshells, to levels representative of a deep space mission. Following exposure to these environments, samples were arcjet tested to representative entry and aerocapture heat rates and loads, at NASA-Ames. Figure 12 shows an impacted SRAM backshell material before, during, and after arcjet testing. Micrometeoroid cavity volumes pre- and post-test can be compared using laser and CT scanning techniques. The testing was completed in August 2012 with the results provided in Reference [44]. Additional information on aerocapture technology developments can be found in the Discovery Program library [27], and in References [45, 46, 47, 48, 49 and 50].
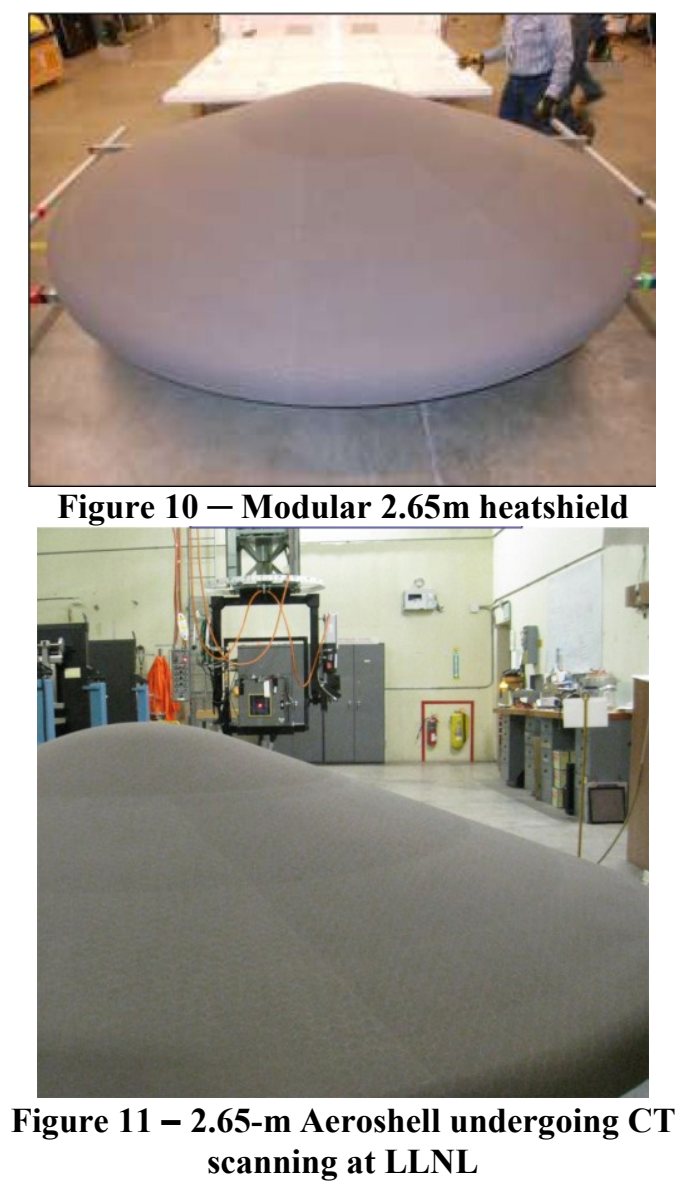

In order to develop and assess the ability of new technologies to enable science missions as well as to define requirements for new technologies, a series of mission studies were performed by the EVT project. A mission study for a direct ballistic entry probe missions to Saturn and Venus were performed in FY-12 using a 45-deg spherecone rigid aeroshell design over a range of entry mass and velocities, aeroshell diameter, and entry flight path angles. Analysis of the results shows the existence of a range of "critical" ballistic coefficients beyond which the steepest possible entries are determined by the pressure limit of the TPS material rather than the deceleration load limit. 
In FY-13, a Uranus mission study was performed. The objectives of the Uranus mission study were to: 1) Establish a range of probe atmospheric entry environments based on
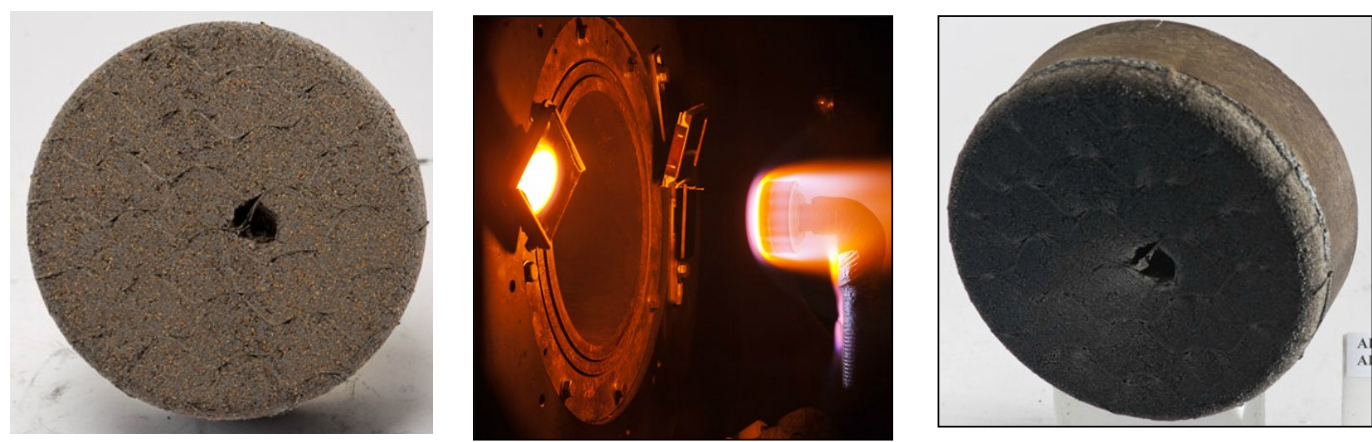

Figure 12 - Space Environmental Effects Testing - simulated micrometeoroid impact followed by arc jet testing landing (EDL) system. [53] Using the MSL sky crane concept places significant environmental, physical envelope and mass limitations on the MAV system options.

Beyond the limitations of the EDL system, the MAV has specific requirements to deliver the orbiting sample (OS) into an orbit suitable for the Earth Return Vehicle (ERV) to rendezvous with and capture the sample. Many of the subsystem

the Uranus Flagship mission outlined in the Planetary Science Decadal Survey for two launch windows: Years 2021 and 2034; 2) Define Uranus entry trade space by performing parametric studies varying vehicle mass and size and entry Flight Path Angle (FPA); 3) Investigate various trajectory options, including direct ballistic entry and aerocapture entry; and 4) Identify entry technologies that could be leveraged to enable a viable mission to Uranus that meets science objectives. Results from both the Venus and Uranus mission studies indicated a need and/or benefit from a new class of thermal protection systems currently under development and referred to as Woven TPS (W-TPS) that could replace heritage carbon-phenolic. Unlike other forms of TPS, W-TPS is formed on a 3-D weaving machine providing engineers greatly enhanced ability to control the TPS properties both laterally and vertically to the vehicles' surface. Characteristics of W-TPS can provide significant reductions in the maximum g-loads experienced during atmospheric entry that can greatly benefit scientific instruments. [51, 52]

\section{Spacecraft Bus and SAMple Return Propulsion TECHNOLOGIES}

\section{Mars Ascent Vehicle (MAV)}

For many years, NASA and the science community have asked for a Mars Sample Return (MSR) mission. There were numerous studies to evaluate MSR mission architectures, technology needs and development plans, and top-level requirements. Because of the challenges, technologically and financially of the MSR mission, NASA initiated a study to look at MSR propulsion technologies through the ISPT Program Office. The objective of the ISPT Program is to develop propulsion technologies that enhance or enable NASA science missions for the Planetary Science Division (PSD) by increasing performance while reducing cost, risk, and/or trip length. The largest propulsion risk element of the MSR mission is the Mars Ascent Vehicle (MAV). The current architecture for the MSR lander is to use the Mars Science Laboratory (MSL) entry, descent, and requirements of the MAV are still to be determined, with many to be defined by the prime integrator during development. However, the driving top-level requirements of the MAV are described in References [4, 54].

Another challenge for the MAV is to meet the environmental requirements for the mission. The environmental requirements include the Earth launch, transit within the cruise stage, the Mars EDL, and finally a long surface stay on Mars. The environments anticipated to influence the system design are the vacuum environment during cruise, the $15 \mathrm{~g}$ quasi-static lateral load during EDL, and the diurnal temperature cycling, as low as $-99^{\circ} \mathrm{C}$ during the surface stay. The thermal requirements necessitate a thermal enclosure or "igloo" in order to maintain practical lander power requirements. A detailed set of requirements

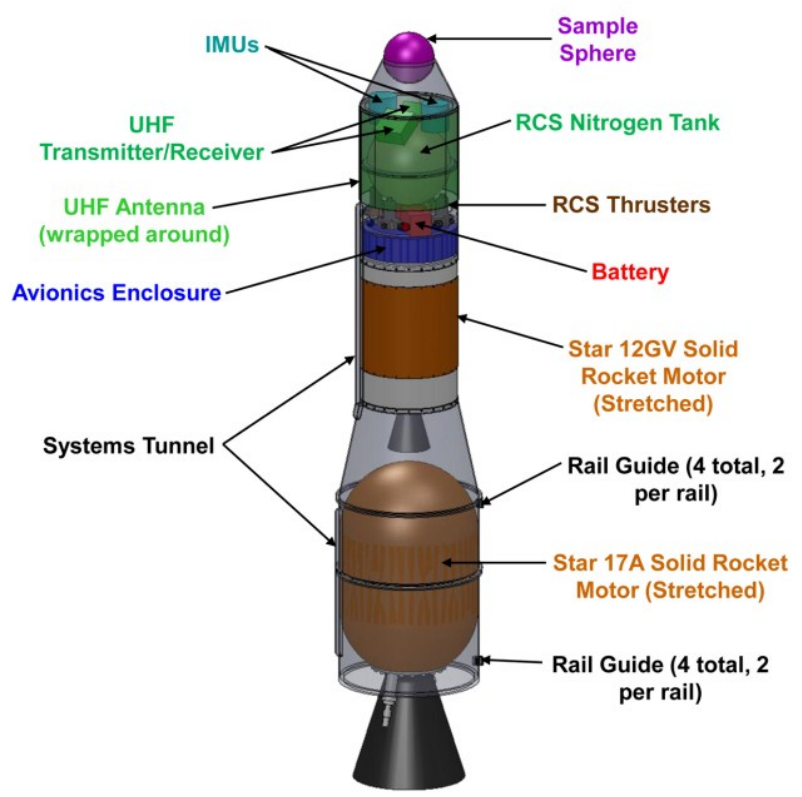

Figure 13 - Government Baseline MAV Concept Design 
and system design standards and guidelines has been established for all study participants to ensure comparable system capability and margins. [55]

Through the NASA Research Announcement (NRA) process, the ISPT program solicited MAV system designs and plans to initiate propulsion system development. Multiple contractors were selected to proceed in October of 2010 and efforts were initiated in February 2011. Awards were made to ATK, Lockheed Martin, and Northrop Grumman to develop MAV concepts using solid-solid, solid-liquid, and liquid-liquid 1 st and 2 nd stage propulsion systems respectively. During the NRA efforts, the contractors completed Principal Investigator led collaborative engineering designs of the MAV and will begin contract options to develop the required technologies in early FY12. Additionally, Firestar Technologies is working, under an SBIR, to develop a Nitrous Oxide Fuel Blend propulsion system applicable to the MAV. [56] The results of the industry efforts indicate that while technology development remains, there are multiple paths to meet performance and requirements of the Mars Ascent Vehicle. The industry efforts and designs are documented in four 2012 IEEE Aerospace Conference papers. [54, 57, 58, 59] The baseline MAV concept design is shown in Figure 13. The Government baseline design is pre-decisional and for understanding design trades and sensitivities, and does not represent any concept selection.

NASA performed system design studies with the Jet Propulsion Laboratory's (JPL) Team-X and GRC's COMPASS teams. [50] The collaborative designs included a system level optimization using the industry designs and an internal "leveled" design to allow comparison of system mass, complexity, and maturity. The trades included the MAV support systems and lander impacts to minimize the total landed mass. The preliminary results of the studies indicate that the baseline solid-solid system appears to offer the lowest mass solution, but it may have challenges achieving the required orbit dispersion accuracies The solidliquid option has a slightly higher mass, imposing more thermal requirements on the lander, but can reduce dispersion errors. The liquid-liquid option has the highest mass growth potential due to its mass fraction relative to a solid motor, but requires the least lander resources and has very tight dispersions. The preliminary NOFBx system evaluation indicates it may be a competitive option, but is unlikely to offer a single stage to orbit solution with a lower mass than the two-stage solid.

Each of the MAV concepts was evaluated for risk and technology maturation and was recommended, primarily in the propulsion elements. The MAV NRA work initially focused on the key risks of the individual propulsion systems at the component level. The MAV project team expects to achieve a milestone in late FY12 to address the key risks of each option and determine the final viability of various concepts. If the most promising MAV concept(s) is viable with respect to mass, volume, and risks, an integrated propulsion stage demonstration would be the next step. If sufficient risk can be reduced through the technology development activities, the final step would be an engineering model MAV development with an objective of a vehicle terrestrial flight demonstration. However, the MAV technology development for the most part is on hold pending the completion of the Mars Program Planning Group (MPPG) activities. Some on-going MAV related studies are being completed, and a long-lead activity to assess the aging of solid rocket motor propellants under Mars environmental conditions (landing shocks and thermal cycling) will proceed until future decisions determine the future MSR architecture and MAV requirements (Figure 14).

New in 2013, NASA initiated the development of a new propellant formulation activity with ATK. NASA and ATK traded a wide range of solid motor propellant formulation options to increase the mechanical properties at low temperatures for hydroxyl terminated polybutadiene (HTPB) and to increase performance for carboxyl terminated polybutadiene (CTPB) formulations. Both HTPB and CTPB propellant options have been found to meet the requirements of the MAV. The higher risk HTPB formulation began a long duration aging test in November of 2013. The propellant aging facility is shown in Figure 14. The propellant will undergo 18 months of testing

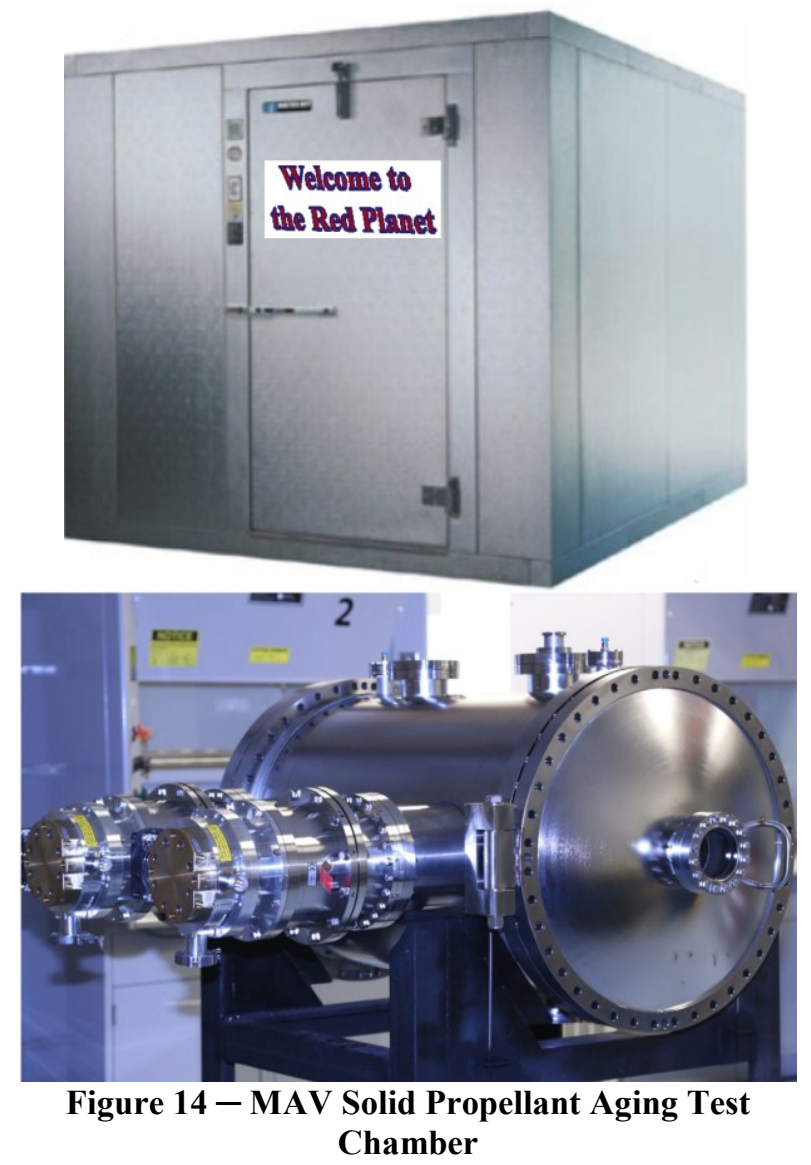

including an initial simulation of the Mars transit at high 
vacuum followed by Mars surface environment of surface pressure and temperature conditions. The sample will be removed at 6-month intervals for performance and mechanical property testing.

\section{Ultra-lightweight Tank Technology (ULTT)}

ISPT invests in the evolution of component technologies that offer significant performance improvements without increasing system level risk. The ISPT Program invested in ultra-lightweight tank technology (ULTT) led by JPL. The ULTT efforts in the past focused on manufacturability and non-destructive evaluation of the lightweight tanks. The tank effort continues to validate defect-detection techniques to maintain NASA standard compliance for ultra-thin wall tanks. The follow-on potential is to develop and qualify positive expulsive ultra-lightweight tanks specifically for the MSL Sky Crane. The Mars Science Laboratory (MSL) Sky Crane, with large propellant tanks, is shown in Figure 15.

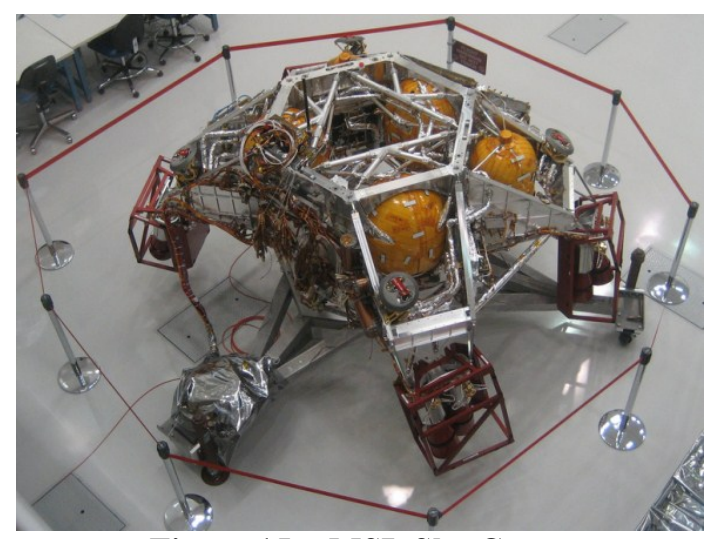

Figure 15 - MSL Sky Crane

The Sky Crane tanks offer mass savings on the order of 24 $\mathrm{kg}$. This is dependent on the final tank wall thickness. The mass reduction would increase the landed mass capability of Sky Crane for a relatively low cost per kg. The Sky Crane Entry Descent Lander (EDL) system could be used again in

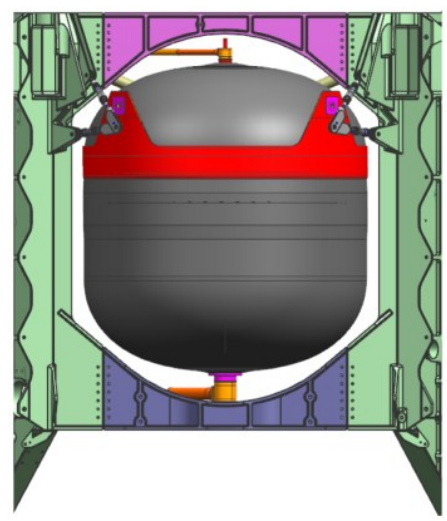

Figure 16 - Ultra-lightweight tank. a future Mars Sample Return (MSR) mission. Both are highly mass constrained. While this particular tank design will be qualified for the Sky Crane application (Figure 16), the ultra-lightweight technology will be applicable for a wide range of future science missions. Propulsion tanks remain the highest dry-mass reduction potential within chemical propulsion systems. This technology would significantly push the state-of-the-art with the promise of a $2 \mathrm{X}$ improvement over conventional tank designs.

The development effort is divided into two main tasks: a Non-Destructive Inspection (NDI) task and the ultralightweight tank design/manufacturing/testing task. The NDI task completed an initial assessment of several NDI techniques, such as eddy-current and surface wave ultrasonic techniques. The results from the tests indicate that these techniques are adequate to find cracks as small as 0.003 inches in the titanium lining. The objective for the NDI task is to establish the crack size that can be detected consistently using these new methods. The ultra-lightweight tank development task would incorporate the NDI technique in the manufacturing and qualification of the new tank.

In order for the tank design to be a success, the approach must demonstrate "safe life." Safe life for non-toxic materials requires proving a design will leak-before-burst. Safe life for toxic liquids, like hydrazine, is more stringent. The NDI technique must be able to detect small cracks in the thin liners, then the NDI results need to be verified, by test, that worst-case crack growth will not grow to failure. An automated eddy current inspection technique has been developed and tested for the detection of small fatigue cracks in thin titanium panels. In this work, a commercially available eddy current probe was deployed on a motion control system in order to obtain high-resolution eddy current C-Scan images of 48 individual samples.

A data processing technique was developed and deployed to enhance the flaw response and automate detection of cracklike indications in the samples. The noise floor of the inspection technique was calculated as three times the standard deviation of the eddy current response in the two unflawed control samples. The remaining 46 samples had fatigue cracks with estimated depths varying between 0.0021 and 0.0067 inches. All the fatigue crack panels registered crack-like indications at a level greater than three times the calculated noise floor. The improved detection capability promises to find 0.003 inch cracks reliably, which represents a $2 \mathrm{x}$ improvement over SOA detection techniques.

The new technique enables the manufacturing of compositeoverwrapped titanium tanks with an anticipated 48 percent mass savings as compared to the heritage Sky Crane tank design. In parallel the ultra-lightweight development work will be completed through a contracted effort with ATK, the suppliers of the MSL tanks. The work will be divided into several phases: design, manufacturing and acceptance/qualification tests. The test phase will include cyclic testing of the flawed liner tank design to demonstrate 
leak-before-burst and safe life requirements. The design phase led to the PDR, which was held in February 2012, and activities are progressing towards CRD in December 2013, which is the likely stopping point of this development effort unless there is interest in a mission user to co-fund the manufacturing and acceptance/qualification test phases.

\section{SYSTEM/MISSION ANALYSIS}

Systems analysis is used during all phases of any propulsion hardware development. The systems analysis area serves two primary functions:

(7) to help define the requirements for new technology development and the figures of merit to prioritize the return on investment,

(8) to develop new tools to easily and accurately determine the mission benefits of new propulsion technologies allowing a more rapid infusion of the propulsion products.

Systems analysis is critical prior to investing in technology development. In today's environment, advanced technology must maintain its relevance through mission pull. Systems analysis is used to identify the future mission needs for decadal missions and Discovery design reference mission (DRMs). The mission studies identify technology gaps, and are used to quantify mission benefits at the system level. This allows studies to guide the investments and define metrics for the technology advancements. Recent systems analysis efforts include quantitative assessment of higher specific impulse Hall thrusters [60], higher thrust-to-power gridded-ion engines, and evaluation of monopropellant system anomalies to assess failure modes and potential mitigation options. In addition to informing project decisions, the mission design studies provide an opportunity to work with the science and user community.

The second focus of the systems analysis project area is the development and maintenance of tools for the mission and systems analyses. Improved and updated tools are critical to allow the potential mission users to quantify the benefits and understand implementation of new technologies. A common set of tools increases confidence in the benefit of ISPT products both for mission planners as well as for potential proposal reviewers. For example, low-thrust trajectory analyses are critical to the infusion of new electric propulsion technology. The ability to calculate the performance benefit of complex electric propulsion missions is intrinsic to the determination of propulsion system requirements. Improved mission design tools demonstrate the ability to enable greater science with reduced risk and/or reduced transit times. Every effort is made to have the ISPT program tools validated, verified, and made publicly available. Additional information on the ISPT tools is available at the ISPT website, http://spaceflightsystems.grc.nasa.gov/Advanced/SciencePr oject/ISPT/LTTT/, including background information and instructions to request the software.
The ISPT office invested in multiple low-thrust trajectory tools that independently verify low thrust trajectories at various degrees of fidelity. The ISPT low-thrust trajectory tools (LTTT) suite includes Mystic [61], the Mission Analysis Low Thrust Optimization (MALTO) [62] 9+6 program, Copernicus [63], and Simulated N-body Analysis Program (SNAP). SNAP is a high fidelity propagator. MALTO is a medium fidelity tool for trajectory analysis and mission design. Copernicus is suitable for both low and high fidelity analyses as a generalized spacecraft trajectory design and optimization program. Mystic is a high fidelity tool capable of N-body analysis and is the primary tool used for trajectory design, analysis, and operations of the Dawn mission. While some of the tools are export controlled, the ISPT web site does offer publicly available tools and includes instructions to request tools with distribution limitations. The ISPT systems analysis project team is conducting a series of courses for training on the ISPT supported trajectory tools. On-going tool advancements include providing MALTO and Mystic on all platforms, bug fixes, and increased capabilities.

The ISPT program awarded three Astrodynamics research grants in 2013. The three awards are research and tool development for outer planet moon tours, low-energy trajectories, and a guess tool to initial Mystic trajectory optimization. The awards were provided to University of Texas-Austin, Purdue University and University of California at Irvine respectively. The efforts were solicited through the SMD ROSES call, started in the spring of 2013, and will conclude in the spring of 2014. The resulting products will be made available to the entire community when complete. Figure 17 is a screenshot from Purdue's low-energy trajectory tool that will interface with GMAT led by NASA GSFC.

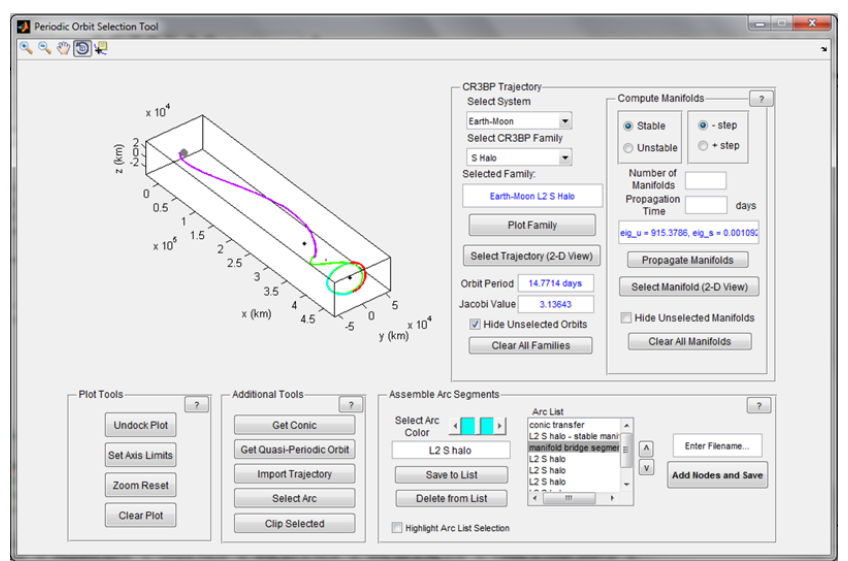

Figure 17 - Low-energy trajectory tool screenshot

ISPT aerocapture project released its Aerocapture Quicklook Tool, formally the multidisciplinary tool for Systems Analysis of Planetary EDL (SAPE). [39] SAPE is a Python based multidisciplinary analysis tool for entry, decent, and landing (EDL) at Venus, Earth, Mars, Jupiter, Saturn, Uranus, Neptune, and Titan. The purpose of the SAPE tool is to provide a method of rapid assessment of 
aerocapture or EDL system performance, characteristics, and requirements. SAPE includes integrated analysis modules for geometry, trajectory, aerodynamics, aerothermal, thermal protection system, and structural sizing. For aerocapture and EDL system designs, systems analysis teams include systems engineers and disciplinary specific experts in flight mechanics, aerodynamics, aerothermodynamics, structural analysis, and thermal protection systems. The systems analysis process may take from several weeks to years to complete. While the role of discipline experts cannot be replaced by any tool, the integrated capabilities of SAPE can automate and streamline several parts of the analysis process significantly reducing the time and cost for preliminary assessment. SAPE continues to receive investment for assessment of Earth Entry Vehicles. [4]

\section{CONClusion}

The ISPT program is currently funded through FY2014. As a result, the focus this year will be concluding on-going efforts, documenting accomplishments, and systematically closing-out the program.

In 2013 and 2014 the NEXT team wraps-up long-duration testing and power processing unit development, and completes closeout documentation. In 2013 HIVHAC completed a test in GRC's VF-5 facility with the same diagnostics suite used for a test of the BPT-4000. This test will help to understand facility effects on Hall thruster testing. The VF-5 facility is undergoing improvements in 2014 to boost its already world-class capabilities, and the program hopes to get the HIVHAC thruster back into the improved facility for another test sequence. HIVHAC will conclude its FY14 activities with verification test of its life extension mechanism, magnetically shielded design iteration, and continued support of the CPE PPU SBIR development. The Ultra-light weight tank (ULTT) will conclude its development at a CDR in January of 2014. The MAV propellant task will continue through early 2015 with an 18-month solid propellant aging test at Mars surface environment conditions.

The ISPT Entry Vehicle Technology (EVT) project completed development, reviewed, and released the baseline Multi-Mission System Analysis for Planetary Entry, Descent and Landing (M-SAPE) tool at the end of FY-13. The EVT project completed spin-tunnel testing of a series of MMEEVs, non-destructive Computed Tomography (CT) scanning of an advanced, modular manufactured $2.65 \mathrm{~m}$ Aeroshell at LLNL, and a Uranus mission study. Plans for FY-14 include completion of the analysis and documentation of the MMEEV spin tunnel and Aeroshell CT scanning data, conclusion of MMEEV thermal soak analyses, development and incorporation of a woven TPS update model in M-SAPE, and Aerocapture and MMEEV closeout tasks in support of ISPT.

The ISPT program is making a concerted effort to adjust the remaining development activities to improve the infusion paths for ISPT developed technologies. The program team is actively seeking out infusion opportunities for the ISPT developed technologies, and is exploring a number of paths to get the technologies out of NASA and into the commercial world. ISPT will continue to support mission infusion. ISPT is leading or co-leading several strategic planning activities that include a Technology Infusion Study, a TRL Assessment Study, and the formulation of development plans for Hall-effect electric propulsion applicable to Discovery-class missions.

The planetary decadal survey identified the need for future work in propulsion, entry vehicles, and spacecraft bus and other platform technologies. ISPT will continue to work with the PSD to identify the propulsion technologies that will be pursued in the future. ISPT will continue to look for ways to reduce system level costs and enhance the infusion process. If the ISPT program concludes in FY2014, the Space Science Projects Office at NASA Glenn will be available to users who have interest in the ISPT-developed technologies. Regardless, if the mission requires electric propulsion, aerocapture, or a conventional chemical system, ISPT technology has the potential to provide significant mission benefits including reduced cost, risk, and trip times, while increasing the overall science capability and mission performance.

\section{ACKNOWLEDGMENTS}

The results and findings presented here are based on work funded by the National Aeronautics and Space Administration, Science Mission Directorate (SMD). ISPT implements the project through task agreements with NASA centers, contracts with industry, and via grants with academic institutions. Implementing NASA centers include Ames Research Center, Glenn Research Center, Jet Propulsion Laboratory, Langley Research Center, and the Marshall Space Flight Center. There are also numerous industry partners in the development of the ISPT products. The authors acknowledge the technical achievements by the respective NASA and contractor teams and the contributions of the respective technology area project managers. In addition, many thanks to Linda Nero for her administrative, editorial, and clerical support of this paper, and to Dan Vento for his editorial reviews and improvements.

\section{REFERENCES}

[1] "Vision and Voyages for Planetary Science in the Decade 2013-2022," The National Academies Press, URL: http://www.nap/edu, 2011

2] Anderson, D. J., Dankanich, J., Hahne, D., Pencil, E. Peterson, T., Munk, M., "Sample Return Propulsion Technology Development under NASA's ISPT Project," 2011 IEEE Aerospace conference, March 2011, Paper \#1115 
[3] Anderson, D. J. Pencil, E. Peterson, T., Dankanich, J., Munk, M., "In-Space Propulsion Technology Products for NASA's Future Science and Exploration Missions," 2011 IEEE Aerospace conference, March 2011, Paper \#1114

[4] Anderson, D. J., Pencil, E., Vento, D., Dankanich, J., Munk, M., Hahne, D., "Propulsion Technology Development for Sample Return Missions under NASA's ISPT Program," AIAA-2011-5766, 47 ${ }^{\text {th }}$ Joint Propulsion Conference, San Diego, CA, July 31 - August 3, 2011.

[5] Anderson, D. J., Pencil, E., Peterson, T., Dankanich, J, and Munk, M., "In-Space Propulsion Technology Products Ready for Infusion on NASA's Future Science Missions," IEEEAC Paper \#1037, 2012 IEEE Aerospace Conference, Big Sky, MT, March 3-10, 2012.

[6] Anderson, D. J., Munk, M., Dankanich, J.,Glaab, L., Pencil, Eric E., and Peterson, T., "Status of Sample Return Propulsion Technology Development under NASA's ISPT Project," IEEEAC Paper \#1038, 2012 IEEE Aerospace Conference, Big Sky, MT, March 3-10, 2012.

[7] Anderson, D. J., Munk, M., Pencil, E., Dankanich, J., Glaab, L., and Peterson, T, "The Status of Spacecraft Bus and Platform Technology Development under the NASA ISPT Program," IEEEAC Paper \#2138, 2013 IEEE Aerospace Conference, Big Sky, MT, March 2-9, 2013

[8] Henderson, S., Stechman, C., Wierenga, K., Miller, S., Liou, L., Alexander, L., and Dankanich, J. W., "Performance Results for the Advanced Materials Bipropellant Rocket (AMBR) Engine," AIAA 2010-6883, 46th Joint Propulsion Conference, Nashville, TN, July 2528,2010 .

[9] Advanced Material Bi-propellant Rocket (AMBR) Information Summary August 2008," New Frontiers Program Library Website http://newfrontiers.larc.nasa.gov/NFPL.html

[10] Liou, L., Dankanich, J. W., and Alexander, L. L., "NASA In-Space Advanced Chemical Propulsion Development in Recent Years," 2010 IEEE Aerospace Conference, Big Sky, MT, March 6-13 2010.

[11] Dankanich, J. W. and McAdams, J., "Interplanetary Electric Propulsion Uranus Mission Trades Supporting the Decadal Survey," AAS 11-189, AAS/AIAA Space Flight Mechanics Meeting, New Orleans, LA, February 13-17, 2011.

[12] Dankanich, J. W., "Electric Propulsion for Small Body Missions," AIAA-2010-6614, 46th AIAA/ASME/SAE/ASEE Joint Propulsion Conference \& Exhibit, Nashville, TN, July 25-28, 2010.
[13] Dankanich, J. W., "Launch Vehicle Savings through Advanced In-Space Propulsion," 9th Low Cost Planetary Missions Conference, Laurel, MD, June 21 - 23, 2011.

[14] 'NASA's Evolutionary Xenon Thruster (NEXT) Ion Propulsion system Information Summary Aug. 2008," New Frontiers Program Library Website URL: http://newfrontiers.larc.nasa.gov/NFPL.html

[15] Pinero, L., Benson, S. W., "NEXT Engineering Model PPU Development, Progress and Plans," AIAA-20115659, 47th AIAA/ASME/SAE/ASEE Joint Propulsion Conference and Exhibit, San Diego, CA, August 2011.

[16] Crofton, M.W., et al., "Characterization of the NASA NEXT Thruster," AIAA-2009-4815, 45th AIAA/ASME/SAE/ASEE Joint Propulsion Conference and Exhibit, Denver, CO, August 2009.

[17] Pollard, J.E., et al., "Spatially-Resolved Beam Current and Charge-State Distributions for the NEXT Ion Engine," AIAA-2010-6779, 46th AIAA/ASME/SAE/ASEE Joint Propulsion Conference and Exhibit, Nashville, TN, August 2010.

[18] Beiting, E.J., Eapen, X.L., and Patterson, M.J., "Effects on Passing Microwave Beams through an Ion Thruster Plume", Paper No. 1841184, published at Space Propulsion 2010 Conference, San Sebastian, Spain, May 3-6, 2010.

[19] Diamant, K.D., et al., "Thrust Stand Characterization of the NASA Evolutionary Xenon Thruster," Journal of Propulsion and Power 2011, 0748-4658 vol.27 no.4 (777785), doi: 10.2514/1.54665.

[20] Diamant, K.D., et al., "Characterization of the NASA NEXT Thruster," AIAA-2009-6701, 45th AIAA/ASME/SAE/ASEE Joint Propulsion Conference and Exhibit, Denver, CO, August 2009.

[21] Mahalingam, S. and Menart, J., "Particle-Based Plasma Simulations for an Ion Engine Discharge Chamber" Journal of Propulsion and Power 2010, 0748-4658 vol.26 no.4 (673-688), doi: 10.2514/1.45954.

[22] Jonell, M., Menart, J., Mahalingam, S., "Particle-Based Plasma Simulation of the NEXT Ion Engine," AIAA2009-4818, 45th AIAA/ASME/SAE/ASEE Joint Propulsion Conference and Exhibit, Denver, CO, August 2009.

[23] Jonell, M., Menart, J., Mahalingam, S., "Particle-in-Cell Model of the NEXT Ion Engine at Three Throttling Conditions," AIAA-2010-6863, 46th AIAA/ASME/SAE/ASEE Joint Propulsion Conference and Exhibit, Nashville, TN, August 2010. 
[24] Mahalingam, S., Choi, Y., Loverich, J., Stolz, P., Jonell, M., Menart, J., "Dynamic Electric Field Calculations Using a Fully Kinetic Ion Thruster Discharge Chamber Model," AIAA-2010-6944, 46th AIAA/ASME/SAE/ASEE Joint Propulsion Conference and Exhibit, Nashville, TN, August 2010.

[25] Mahalingam, S., Choi, Y., Loverich, J., Stoltz, P., Bias, B., and Menart, J., "Fully Coupled Electric Field/PICMMC Simulation Results of the Plasma in the Discharge Chamber of an Ion Engine," AIAA-2011-6071, 47th AIAA/ASME/SAE/ASEE Joint Propulsion Conference and Exhibit, San Diego, CA, August 2011.

[26] Bias, B., Penkal, B., Jonell, M., Menart, J., and Mahalingam, S., "Off Design Simulation Results of Several Operating Conditions of the NEXT Discharge Chamber," AIAA-2011-5660, 45th AIAA/ASME/SAE/ASEE Joint Propulsion Conference and Exhibit, San Diego, CA, August 2011

[27] Program Library Website URL: http://discovery.larc.nasa.gov/dpl.html

[28] New Frontiers Program Library Website URL: http://newfrontiers.larc.nasa.gov/NFPL.html

[29] Soulas, G., et al., "The Impact of Back-Sputtered Carbon on the Accelerator Grid Wear Rates of the NEXT and NSTAR Ion Thrusters", IEPC-2013-157, 33 ${ }^{\text {rd }}$ International Electric Propulsion Conference, Washington, DC, October 6-10, 2013.

[30] Shastry, R., et al., Status of NASA's Evolutionary Xenon Thruster (NEXT) Long-Duration Test as of 50,000 $\mathrm{h}$ and $900 \mathrm{~kg}$ Throughput", IEPC-2013-121, 33 ${ }^{\text {rd }}$ International Electric Propulsion Conference, Washington, DC, October 6-10, 2013.

[31] Kamhawi, H., "Overview of the High voltage Hall Accelerator Project," AIAA-2009-5282, 45th AIAA/ASME/SAE/ASEE Joint Propulsion Conference and Exhibit, Denver, CO, August 2009.

[32] Huang, W., et al., "Effect of Background Pressure on the Performance and Plume of the HIVHAC Hall Thruster", IEPC-2013-058, 33 ${ }^{\text {rd }}$ International Electric Propulsion Conference, Washington, DC, October 6-10, 2013.

[33] Dankanich, J. Cardin, J., Dien, A., Netwall, C., Osborn, M., and Kamhawi, H., "Advanced Xenon Feed System (AXFS) Development and Hot-fire Testing," AIAA2009-4910, 45 ${ }^{\text {th }}$ Joint Propulsion Conference, Denver, CO, August 2-6, 2009.

[34] Kamhawi, H., et al., "High Voltage Hall Accelerator Project Overview," IEPC-2009-092, Proceedings of the 31st International Electric Propulsion Conference, Ann Arbor, MI, September 2009.
[35] Kamhawi, H., Haag, T., Pinero, L., Huang, W. Peterson, T., Manzella, D., Dankanich, J., Mathers, A., Hobson, D., "Overview of the Development of a LowCost High Voltage Hall Accelerator Propulsion System for NASA Science Missions," AIAA-2011-5520, 47th AIAA/ASME/SAE/ASEE Joint Propulsion Conference and Exhibit, San Diego, CA, August 2011.

[36] Kamhawi, H., et al., "Single String Integration of the HiVHAc Voltage Hall Accelerator in NASA Glenn Vacuum Facility 5," IEPC-2013-445, 33 ${ }^{\text {rd }}$ International Electric Propulsion Conference, Washington, DC, October 6-10, 2013.

[37] Kamhawi, H., et al., "Investigation of the Effects of Pressure and Cathode Flow Split and Position on the Performance of the High Voltage Hall Accelerator Thruster," IEPC-2013-446, 33 ${ }^{\text {rd }}$ International Electric Propulsion Conference, Washington, DC, October 6-10, 2013.

[38] Lee, B., et al., "Real-Time Boron Nitride Erosion Measurements of the HIVHAC Thruster via Cavity RingDown Spectroscopy", IEPC-2013-119, $33^{\text {rd }}$ International Electric Propulsion Conference, Washington, DC, October 6-10, 2013.

[39] Samareh, Jamshid A., Maddock, Robert W., and Winski, Richard G., "An Integrated Tool for System Analysis of Sample Return Vehicles," IEEEAC Paper \#1169, 2012 IEEE Aerospace Conference, Big Sky, MT, March 3-10, 2012

[40] Agrawal, P., Sepka, S., Aliaga, J., Venkatapathy, E., Samareh, J., "Thermal Soak Analysis of Earth Entry Vehicles," AIAA-2012-3010, 43rd Thermophysics Conference, New Orleans, LA, June 25-28, 2012.

[41] Patterson, Byron W.; Glaab, Louis J.: "Uniform Foam Crush Testing for Multi-Mission Earth Entry Vehicle Impact Attenuation". NASA TM-2012-217763, August 2012.

[42] Glaab, Louis; Agrawal, Parul; Hawbaker, James: "Impact Foam Testing for Multi-Mission Earth Entry Vehicle Applications". International Planetary Probe Workshop, San Jose, CA, 2013.

[43] Anderson, D. J., Dankanich, J., Munk, M., Pencil, E., Liou, L., "The NASA In-Space Propulsion Technology Project's Current Products, and Future Directions," 2010 IEEE Aerospace Conference, March 2010, Paper \#1078

[44] Agrawal, Parul; Munk, Michelle M.; Glaab, Louis J.; "Arcjet Testing of Micro-Meteoroid Impacted Thermal Protection Materials", AIAA TP-2013(?). 
[45] Congdon, W. M., "Family Systems of Advanced Charring Ablators for Planetary Aerocapture and Entry Missions," 1st NSTC, University of Maryland, June 1921, 2007.

[46] Wright, M. J., Bose, D., and Olejniczak, J., "The Effect of Flowfield-Radiation Coupling on Aeroheating for Titan Aerocapture", AIAA Paper No. 2004-0484, presented at the 42nd AIAA Aerospace Sciences Conference and Exhibit, Reno, Nevada, Jan. 2004.

[47] Wright, M. J., Bose, D., and Chen, Y. K., "Probabilistic Modeling of Aerothermal and Thermal Protection Material Response Uncertainties," 53rd JANNAF Joint Propulsion Meeting, Dec. 2005.

[48] Willcockson, W. W., NASA Contractor Report (pending), "Final Summary Report: Aerocapture Aeroshell Technologies (AAT) Program," January 31, 2007.

[49] Miller, K. L. et al., NASA Contractor Report (pending), "Ultralight-weight Ballute Technology for Aerocapture and Aeroassist Missions," January 2007.

[50] Reza, S., NASA Contractor Report (pending), "Aerocapture Inflatable Decelerator: Lockheed Martin Inflatable Aeroshell Final Report,” January 11, 2007.

[51] Prabhu, Dinesh K.; Allen, Gary A. Jr.; Cappuccio, Gelsomina; Spilker, Thomas R.; Hwang, Helen H.; Moses, Robert W.: "Atmospheric Entry Studies for Saturn Missions: $45^{\circ}$ Sphere-Cone Rigid Aeroshells and Ballistic Entries", presented at the $10^{\text {th }}$ International Planetary Probe Workshop, San Jose, CA, June 2013.

[52] Prabhu, Dinesh K.; Allen, Gary A. Jr.; Cappuccio, Gelsomina; Spilker, Thomas R.; Hwang, Helen H.; Moses, Robert W.: "Ballistic Entries at Venus", presented at the $10^{\text {th }}$ International Planetary Probe Workshop, San Jose, CA, June 2013.

[53] Mattingly, R., and May, L., "Mars Sample Return as a Campaign," IEEEAC Paper \#1805, 2011 IEEE Aerospace Conference, Big Sky, MT, March 5-12, 2011.

[54] Dankanich, John W., and Klein, Eric, "Mars Ascent Vehicle Development Status," IEEEAC Paper \#1471, 2012 IEEE Aerospace Conference, Big Sky, MT, March 3-10, 2012.

[55] Mattingly, R. M., "Mars Sample Return MAV Study Guidelines,” JPL D-66683 Rev. B, May, 2011.

[56] Mungas, Greg, Fisher, David, Vozoff, Joanne, and Villa, Marco, "NOFBX"M Single Stage to Orbit Mars Ascent Vehicle," IEEEAC Paper \#1809, 2012 IEEE Aerospace Conference, Big Sky, MT, March 3-10, 2012.
[57] Ross, Douglas, Russell, James, and Sutter, Brian, "Mars Ascent Vehicle (MAV): Designing for High Heritage and Low Risk," IEEEAC Paper \#1190, 2012 IEEE Aerospace Conference, Big Sky, MT, March 3-10, 2012.

[58] Trinidad, Mark A., Zabrensky, Ed, and Sengupta, Anita, "Mars Ascent Vehicle System Studies and Baseline Conceptual Design," IEEEAC Paper \#1744, 2012 IEEE Aerospace Conference, Big Sky, MT, March 3-10, 2012.

[59] Sengupta, Anita, Pauken, Mike, Kennett, Andrew, Trinidad, Mark A., and Zabrensky, Ed, "Systems Engineering and Technology Considerations of a Mars Ascent Vehicle," IEEEAC Paper \#1511, 2012 IEEE Aerospace Conference, Big Sky, MT, March 3-10, 2012.

[60] Dankanich, J. W., Kamhawi, H., and Mathers, A., "HiVHAC Maximum Operating Power Mission Impacts," IEPC-2009-213, 2009 International Electric Propulsion Conference, Ann Arbor, MI, September 20-24, 2009.

[61] Whiffen, G., "Mystic: Implementation of the Static Dynamic Optimal Control Algorithm for High-Fidelity Low-Thrust Trajectory Design," AIAA-2006-6741, AIAA/AAS Astrodynamics Specialist Conference, Keystone, CO, August 21-24, 2006.

[62] Sims, J., Finlayson, P., Rinderle, E., Vavrina, M., and Kowalkowski, T., "Implementation of a Low-Thrust Trajectory Optimization Algorithm for Preliminary Design," AIAA-2006-6746, AIAA/AAS Astrodynamics Specialist Conference, Keystone, CO, August 21-24, 2006.

[63] Ocampo, C., Senent, J. S., and Williams, J., "Theoretical Foundation of Copernicus: A Unified System for Trajectory Design and Optimization," NASA Technical Reports Server, Document ID: 20100017708; Report Number: JSC-CN-20552, May, 21, 2010. 


\section{BIOGRAPHIES}

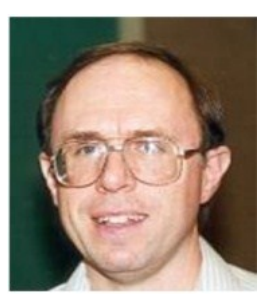

David Anderson is a program manager in the Space Science Project Office at the NASA Glenn Research Center (GRC). Mr. Anderson has been working at NASA for over 20 years, and worked for the USAF for 10 years prior to joining NASA. He is currently the Program Manager for the In-Space Propulsion Technology (ISPT) program, and is the SBIR Spacecraft and Platform Subsystems Topic Manager. Formerly, he managed the advanced Radioisotope Power System (RPS) efforts at NASA GRC, was active with new business development and proposal development activities. He worked in GRC's Systems Management Office, where he was involved in project management oversight activities and led or was involved in several Center and NASA-wide program/project management process improvement teams or activities. He has a B.S. in Aerospace Engineering from the University of Cincinnati and an M.S. in Engineering Management from the Cleveland State University.

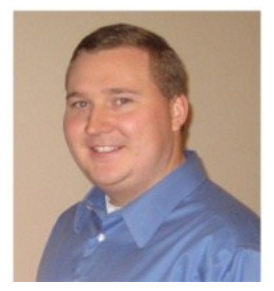

John Dankanich was formerly a Gray Research contractor to the NASA Glenn Research Center. He presently is at NASA Marshall Space Flight Center. At Glenn Research Center, he was the electric propulsion lead systems engineer for the ISPT program. He also served as a mission and systems analyst for the ISPT program. John has expertise in mission and systems analyses, electric propulsion systems, and trajectory optimization. He supported propulsion system development, Mars ascent vehicle design, lunar lander guidance simulations, planetary defense studies, and advanced propulsion design and testing. John has a B.S. in Physics and Aerospace Engineering and an M.S. in Aerospace Engineering from Purdue University.

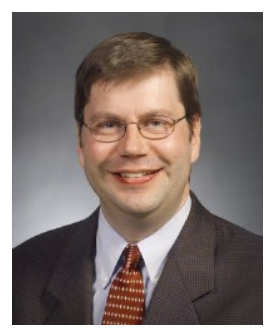

Eric Pencil is Propulsion Projects Area Manager for the In-Space Propulsion Technology Office at NASA Glenn Research Center. He is responsible for the management and execution of the electric propulsion development tasks for NASA Science missions. Previously he worked as a project/research engineer in the electric propulsion research group in which he worked on various electric propulsion technologies at varying stages of maturity from basic research to flight hardware.

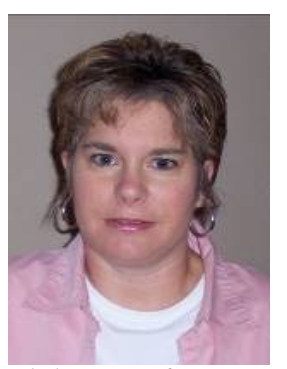

Michelle Munk has been a NASA employee for nearly 20 years, first at the Johnson Space Center, then at the Langley Research Center. She has been involved in Mars advanced mission studies for many years, both robotic and human, contributing interplanetary trajectory analysis and entry and descent analysis. She managed the delivery of International Space Station hardware, and was on the Mars Odyssey aerobraking operations team. In 2002, Ms. Munk accepted a detail assignment to become the Lead Engineer for Aerocapture Technology Development under In-Space Propulsion at Marshall Space Flight Center. She managed the technical work of ISP Aerocapture for nearly five years before becoming the Project Area Manager and returning to Langley in 2007. Ms. Munk is also involved in the Mars Science Laboratory Entry, Descent and Landing Instrumentation (MEDLI) project and contributes to other NASA projects developing entry system technologies. She has a BSAE from Virginia Tech and completed graduate coursework at the University of Houston.

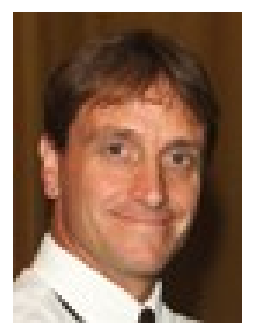

Lou Glaab is currently an assistant project manager in the Entry Vehicle Technology area. Mr. Glaab has been working at NASA for over 25 years. His experience at NASA includes aircraft stability and control, crew-vehicle interface design, unmanned ariel vehicles, and aerosciences for the Constellation Program (CxP). He has a B.S. in Aerospace Engineering from the University of Buffalo, NY, and an M.S. in Aeronautical Engineering from George Washington University.

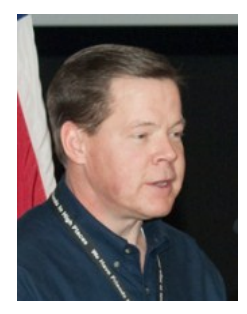

Todd Peterson is a project manager in the Space Science Project Office at the NASA Glenn Research Center (GRC). With over 26 years of space flight project experience at NASA GRC, he has extensive propulsion, power and communication system project management experience in human and robotic space flight projects (Space Station, Shuttle/Mir, Deep Space-1, Earth Observer-1, Lunar Reconnaissance Orbiter) and development projects (electric propulsion, chemical propulsion, photovoltaic \& dynamic power systems, microgravity research). He has a B.S. in Mechanical Engineering from the University of Akron and an M.S. in Mechanical Engineering from Cleveland State University. 